\title{
Coupled thermal-hydrological-mechanical analyses of the Yucca Mountain Drift Scale Test-Comparison of field measurements to predictions of four different numerical models
}

\author{
J. Rutqvist ${ }^{\mathrm{a}, *}$, D. Barr ${ }^{\mathrm{b}}$, R. Datta ${ }^{\mathrm{c}}$, A. Gens ${ }^{\mathrm{d}}$, A. Millard ${ }^{\mathrm{e}}$, S. Olivella ${ }^{\mathrm{d}}$, \\ C.-F. Tsang ${ }^{\mathrm{a}}$, Y. Tsang ${ }^{\mathrm{a}}$ \\ ${ }^{a}$ Lawrence Berkeley National Laboratory (LBNL), Earth Sciences Division, MS 90-1116, 1 Cyclotron Road, Berkeley, CA 947 20, USA \\ ${ }^{\mathrm{b}}$ Office of Repository Development, US Department of Energy, POB 30307, N. Las Vegas, NV 890 36, USA \\ ${ }^{\mathrm{c}}$ Bechtel SAIC Company, 1180 Town Center Dr., Las Vegas, NV 89144, USA \\ ${ }^{\mathrm{d}}$ Geotechnical Engineering Department, Technical University of Catalunya, Jordi Girona 1-3, Edificio D-2, Barcelona 08034, Spain \\ ${ }^{\mathrm{e}}$ Commissariat a l'Energie Atomique, Saclay, Gif/Yvette 91191, France
}

Accepted 2 March 2005

Available online 4 May 2005

\begin{abstract}
The Yucca Mountain Drift Scale Test (DST) is a multiyear, large-scale underground heating test designed to study coupled thermal-hydrological-mechanical-chemical behavior in unsaturated fractured and welded tuff. As part of the international cooperative code-comparison project DEvelopment of COupled models and their VALidation against EXperiments, four research teams used four different numerical models to simulate and predict coupled thermal-hydrological-mechanical (THM) processes at the DST. The simulated processes included heat transfer, liquid and vapor water movements, rock-mass stress and displacement, and stress-induced changes in fracture permeability. Model predictions were evaluated by comparison to measurements of temperature, water saturation, displacement, and air permeability. The generally good agreement between simulated and measured THM data shows that adopted continuum model approaches are adequate for simulating relevant coupled THM processes at the DST. Moreover, thermal-mechanically induced rock-mass deformations were reasonably well predicted using elastic models, although some individual displacements appeared to be better captured using an elasto-plastic model. It is concluded that fracture closure/opening caused by change in normal stress across fractures is the dominant mechanism for thermal-stressinduced changes in intrinsic fracture permeability at the DST, whereas fracture shear dilation appears to be less significant. This indicates that such changes in intrinsic permeability at the DST, which are within one order of magnitude, are likely to be mostly reversible.
\end{abstract}

(C) 2005 Elsevier Ltd. All rights reserved.

Keywords: Coupled processes; Modeling; Thermal; Hydrological; Mechanical; Measurements; Permeability; Fractured rock

\section{Introduction}

The Yucca Mountain Drift Scale Test (DST) is a multiyear, large-scale underground heating test conducted by the US Department of Energy's program for

\footnotetext{
*Corresponding author. Tel.: + 15104865432 ; fax: +15104865686 .

E-mail address: jrutqvist@lbl.gov (J. Rutqvist).
}

studying the coupled thermal-hydrological-mechanical-chemical behavior in unsaturated fractured and welded tuff at Yucca Mountain, Nevada. As part of the international cooperative project DEvelopment of COupled models and their VALidation against EXperiments, project phase III (DECOVALEX III), four research teams used four different numerical models to simulate and predict coupled thermal-hydrological-mechanical (THM) processes at the DST (Table 1). The 


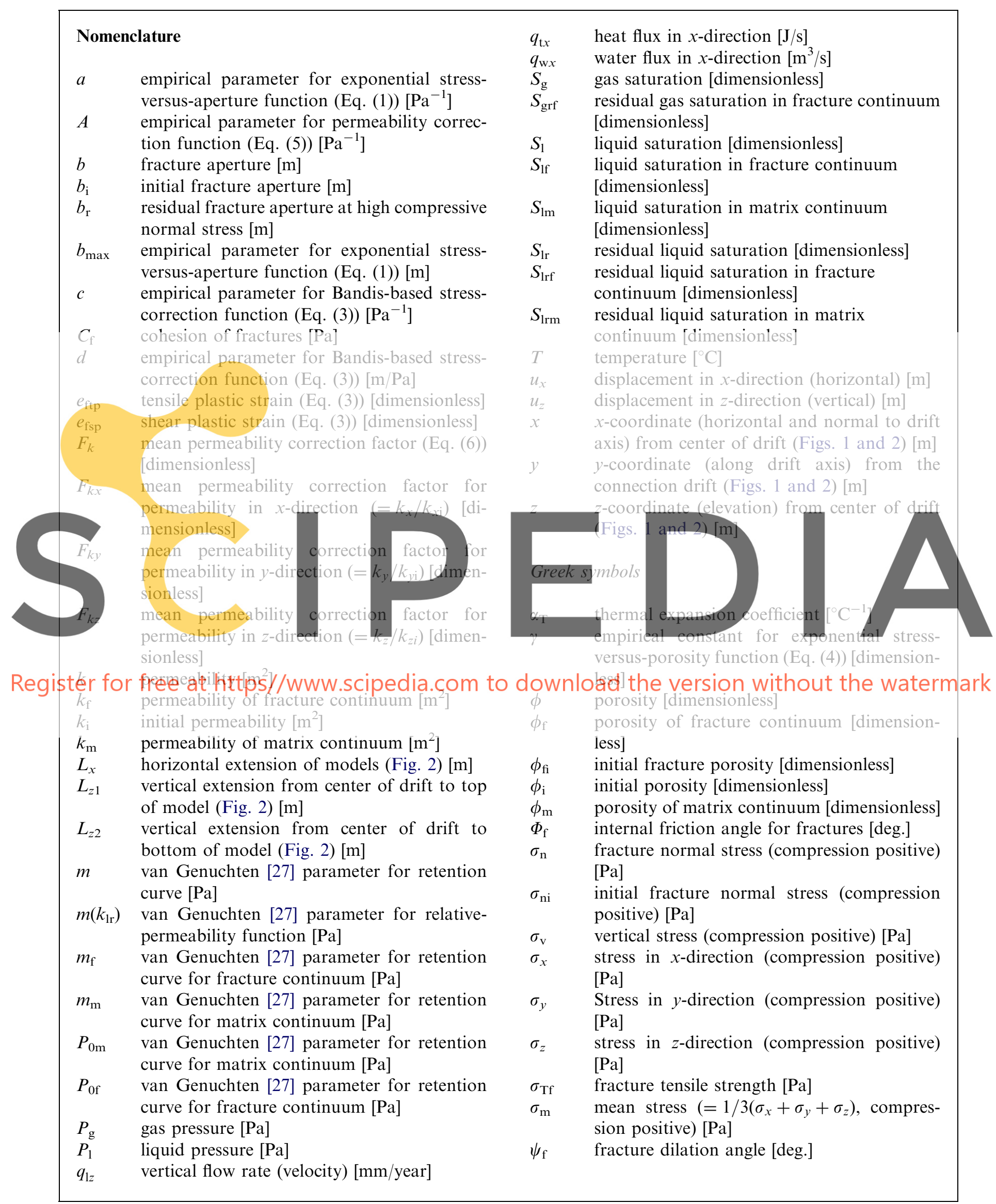


simulated THM process includes heat transfer by conduction and convection, liquid and vapor water movements, rock stress and displacements, and stressinduced changes in fracture permeability. The predicted THM responses were compared to in situ measurements of temperature, water saturation (estimated through geophysical measurements), rock-mass displacement, and changes in permeability estimated through airinjection tests.

This paper discusses and compares simulation results on coupled THM processes by all four research teams, and their match to measured data at the DST. The DST and the four numerical models [1-5] are briefly described in this paper. More comprehensive descriptions of experimental data and model approaches used by the individual research teams can be found in several papers [6-10] in a recent issue (on coupled THMC processes) of Elsevier's Geo-Engineering Book Series. Additional results by two of the research teams, as well as results on coupled thermal-hydrological-chemical analyses, are presented in three companion papers in this issue of the journal [11-13]. A comprehensive presentation of the DST and experimental data can be found in a Yucca

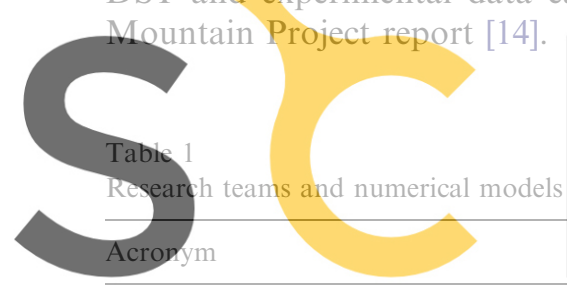

CEA
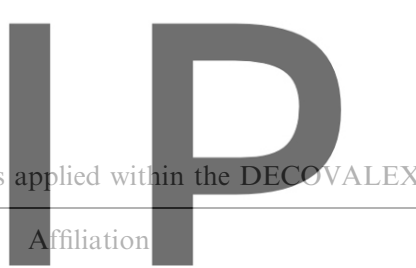

Commissariat a l'Energie Atomique. France

\section{The Yucca Mountain DST}

The ongoing DST is located at Yucca Mountain, Nevada, in a side alcove of an underground tunnel, the Exploratory Studies Facility (ESF), at a depth of about $250 \mathrm{~m}$ in the so-called middle nonlithophysal zone (Tptpmn) of the Topopah Spring Tuff formation. The DST centers around a heated drift, $5 \mathrm{~m}$ in diameter and $50 \mathrm{~m}$ long (Fig. 1). Heating is provided by floor heaters along a $47.5 \mathrm{~m}$ long section of the heated drift, as well as by 50 rod heaters, referred to as "wing heaters", which are placed into horizontal boreholes emanating from, and orthogonal to the heated drift (Fig. 1). The dimensions of the heated drift are similar to the current design of waste emplacement drifts for a repository at Yucca Mountain. The heaters of the DST were activated on December 3, 1997. The heating phase continued for approximately 4 years, until January 14, 2002, when heater power was turned off. Currently, the DST is in the midst of a 4-year period of natural cooling.

Measurements at the DST include laboratory and field characterization of the near-field rock massdenoted hereafter as the "DST test block". Preheat

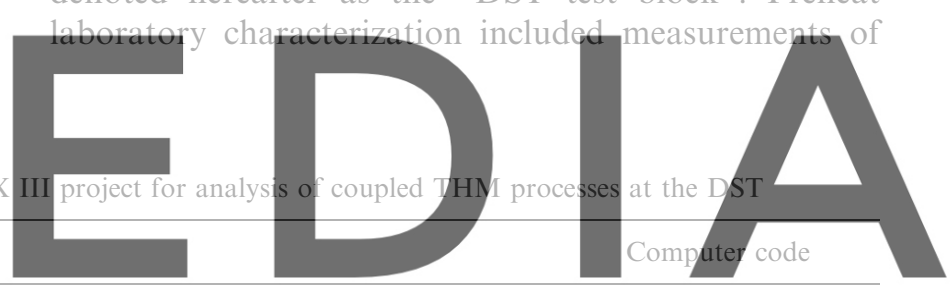

CASTEM2000 [1]

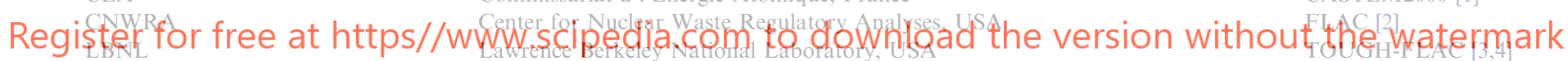
UPC Technical University of Catalunya, Spain CODE_BRIGHT [5]

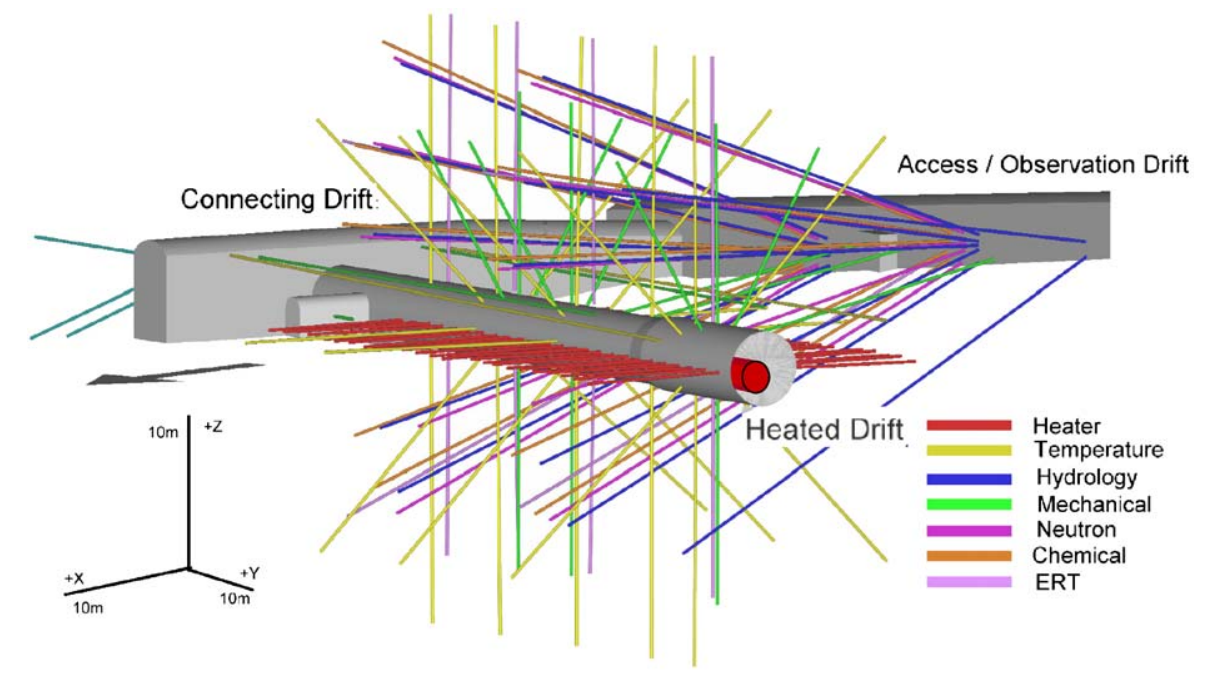

Fig. 1. Three-dimensional view of the Yucca Mountain DST. The color-coded lines indicate boreholes for various measurements of thermally driven THMC responses. 
thermal, hydrological, and mechanical properties, mineral-petrology studies, and pore-water chemical and isotopic analysis. Preheat field characterization of the DST test block involved rock-mass classification, fracture mapping, video logging of boreholes, geophysical measurements, and air-permeability testing.

After activation of the heaters, passive monitoring and active testing were conducted during the heating phase and are still ongoing as part of the subsequent cooling phase. The DST test block has been instrumented with thousands of sensors to monitor the thermal, mechanical, hydrological, and chemical processes on at least an hourly basis [14]. In Fig. 1, the instrumented boreholes are color-coded according to their functions. For the purposes of studying THM processes, the focus is on boreholes designed to measure thermal (yellow), hydrological (blue), and mechanical (green) responses. Radial arrays of $20 \mathrm{~m}$ long boreholes emanating from the heated drift monitor the temperature evolution, as do longitudinal boreholes parallel to the heated drift. Temperature sensors in each borehole are installed at approximately $30 \mathrm{~cm}$ intervals. Most boreholes labeled as "hydrology" in Fig. 1 originate from the observation

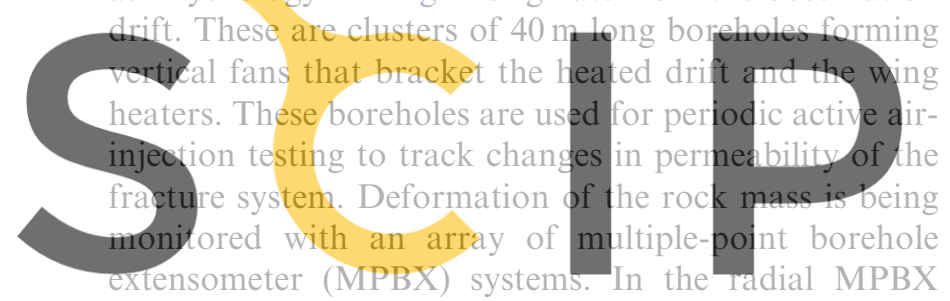
boreholes, four anchors attach to the borehole wall at a

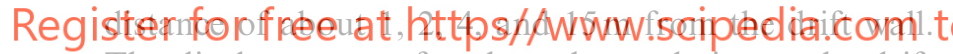
The displacements of each anchor, relative to the drift wall, are continuously monitored.

\section{Computational models}

Computational models for simulating coupled THM processes at the DST are briefly presented in this section. First, computational models and experiences in previously published thermal-hydrological $(\mathrm{TH})$ and TM analyses of the DST are reviewed in Section 3.1. These $\mathrm{TH}$ and TM analyses provided guidance for the research teams of the DECOVALEX III project in developing appropriate coupled THM models of the DST. The four computational models used for development of coupled THM model results compiled in this paper are briefly described in Section 3.2.

\subsection{Previous coupled TH and TM analyses of the DST}

Pre-test predictions of coupled TH and TM processes at the DST have been conducted as a part of the Yucca Mountain site characterization project. These predictions include three-dimensional simulations of $\mathrm{TH}$ processes conducted by the Lawrence Berkeley National Laboratory (LBNL) using the TOUGH2 code $[15,16]$ and by the Lawrence Livermore National Laboratory using the NUFT code [17]. Coupled TM processes have been simulated by the Sandia National Laboratories using the JAS-3D code $[18,19]$ and by the Lawrence Livermore National Laboratory using the 3-DEC code [20]. However, no fully coupled THM analysis of the DST was performed until recently, when Rutqvist and co-workers $[3,4]$ applied a model for the analysis of coupled THM processes under multiphase flow conditions.

In the pre-test prediction of coupled $\mathrm{TH}$ processes at the DST, Birkholzer and Tsang [15,16] developed a three-dimensional numerical model based on previous experiences in simulating the Yucca Mountain Single Heater Test (SHT) in the same formation [21]. The modeling of the SHT had shown that a continuum model, and in particular an overlapping continuum model, is appropriate for modeling fracture and matrix interactions with multiphase, multicomponent fluid flow and heat transfer. As a result, an overlapping continuum model, or more specifically, a dual-permeability model

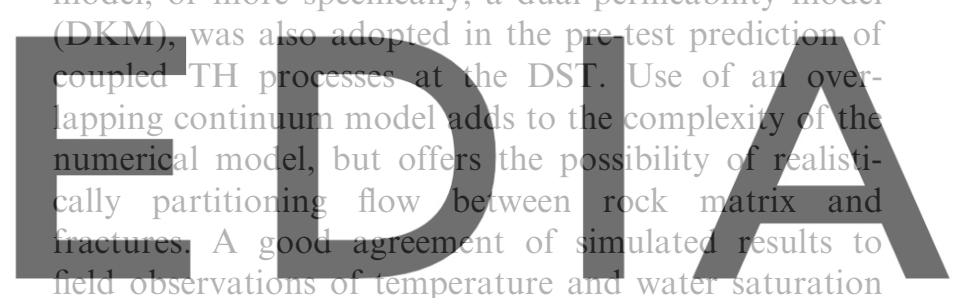

(estimated through geophysical methods) reported in

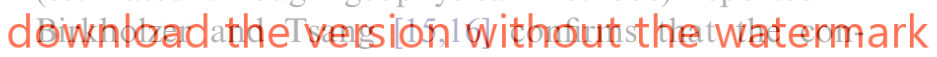
tinuum approach and the DKM model are adequate for simulating coupled TH processes in the fractured volcanic tuff surrounding the DST.

In a pre-test prediction of coupled TM processes at the DST, Francis et al. [18] and Sobolik et al. [19] applied a ubiquitously fractured continuum model approach that was also based on previous experiences in modeling the SHT [22]. The TM analyses of the SHT had shown that rock-mass deformations in the Tptpmn unit were reasonably well captured with the continuum approach and a linear-elastic or nonlinear-elastic mechanical model [22]. A continuum approach and a ubiquitous joint model were also applied in the pretest predictions of coupled TM processes at the DST $[18,19]$. A reasonable good agreement between simulated and measured displacements at the DST confirmed the appropriateness of the continuum approach. Furthermore, a comparison between simulation results of a discrete-fracture model and a continuum model by Blair [20] showed minor differences regarding mechanical displacements. This indicates the dominance of thermo-elastic expansion of the rock matrix, although locally a small slip may occur on fracture planes. 


\subsection{Justification for continuum-based THM models of the DST}

One significant finding from previous $\mathrm{TH}$ and TM analyses of the DST described above, as well as preliminary THM analysis by Rutqvist and Tsang [4], is that a continuum approach is sufficient to simulate the main coupled THM processes at the DST. A continuum approach is appropriate in this case because the volcanic tuff formation, in which the DST is located, is intensively fractured, with a mean fracture spacing less than $0.3 \mathrm{~m}$. Fracture mapping along the ESF displays three dominant fracture sets [23]:

(1) one prominent vertical, southeast trending

(2) one less prominent vertical, southwest trending,

(3) one less prominent subhorizontal,

with the southeast trending fracture set being roughly parallel to the heated drift. In addition, a set of randomly oriented fractures accounts for about 30\% of the mapped fractures. The average spacing for

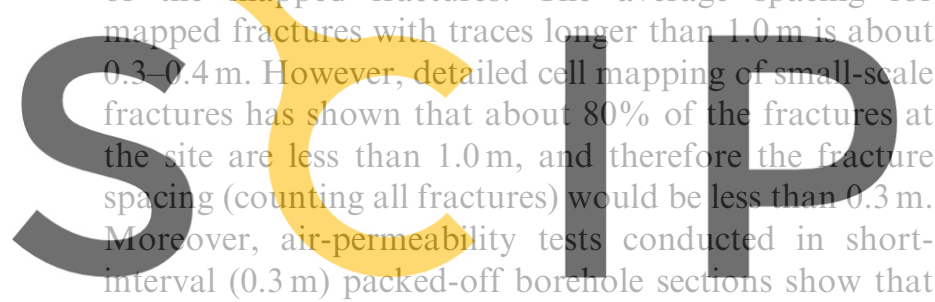

hydraulic conducting fractures exist at least every $0.3 \mathrm{~m}$

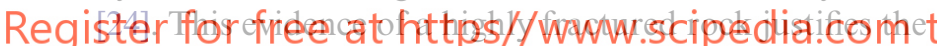

use of a continuum modeling approach. Furthermore, important interactions between fracture and matrix fluid flow can be readily simulated using a continuum model, such as the above-mentioned DKM approach. Consequently, the four computational models applied within the DECOVALEX III project for analysis of coupled THM processes at the DST are all continuum based.

\subsection{Computational models for coupled THM analysis within DECOVALEX III}

The codes and basic approaches used by the four research teams (Table 1) within the DECOVALEX III project are presented in Table 2. The LBNL and UPC teams performed coupled THM analyses that included modeling of two-phase fluid flow (gas and liquid), heat transfer (conduction and convection), and mechanical stress and strain. LBNL used the DKM approach for simulation of TH processes, whereas UPC used an equivalent continuum model. In the equivalent continuum model, the effects of fractures and rock matrix are lumped into one continuum, with average equivalent

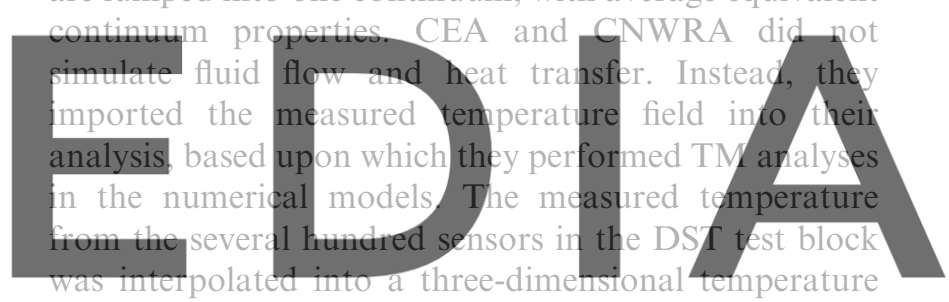

field, which in turn was interpolated to nodal points in

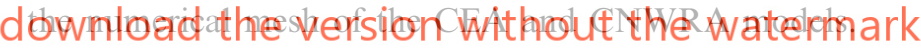

Table 2

Codes and basic modeling approaches used by each research team for modeling of coupled THM processes at the Yucca Mountain DST

\begin{tabular}{|c|c|c|c|c|c|}
\hline Team & $\begin{array}{l}\text { Numerical } \\
\text { simulator }\end{array}$ & Couplings considered & Mechanical model & Hydraulic model & $\begin{array}{l}\text { Hydromechanical } \\
\text { model }\end{array}$ \\
\hline LBNL & $\begin{array}{l}\text { TOUGH- } \\
\text { FLAC }\end{array}$ & THM & Elastic & $\begin{array}{l}\text { Dual permeability } \\
\text { model with interacting } \\
\text { matrix and fracture } \\
\text { continua }\end{array}$ & $\begin{array}{l}\text { Permeability correlated } \\
\text { to fracture aperture } \\
\text { (and normal stress) } \\
\text { assuming three } \\
\text { orthogonal fractures } \\
\text { sets }\end{array}$ \\
\hline UPC & $\begin{array}{l}\text { CODE- } \\
\text { BRIGHT }\end{array}$ & THM & Elastic & $\begin{array}{l}\text { Single continuum } \\
\text { model }^{\mathrm{a}} \text { with continuum } \\
\text { equivalent properties }\end{array}$ & $\begin{array}{l}\text { Permeability correlated } \\
\text { to porosity (and } \\
\text { volumetric strain) }\end{array}$ \\
\hline CEA & CASTEM & $\begin{array}{l}\text { TM upon measured } \\
\text { temperature field }\end{array}$ & $\begin{array}{l}\text { Elasto-brittle or elasto- } \\
\text { plastic ubiquitous joint } \\
\text { model }\end{array}$ & $\mathrm{N} / \mathrm{A}$ & $\mathrm{N} / \mathrm{A}$ \\
\hline CNWRA & FLAC & $\begin{array}{l}\text { TM upon measured } \\
\text { temperature field }\end{array}$ & $\begin{array}{l}\text { Elasto-plastic } \\
\text { Mohr-Coulomb or } \\
\text { ubiquitous joint model }\end{array}$ & $\mathrm{N} / \mathrm{A}^{\mathrm{b}}$ & $\begin{array}{l}\text { Permeability correlated } \\
\text { to fracture aperture } \\
\text { (and normal stress and } \\
\text { plastic strain) assuming } \\
\text { two orthogonal fracture } \\
\text { sets }\end{array}$ \\
\hline
\end{tabular}

${ }^{a}$ UPC also applied a dual-continuum model for separate TH analysis [6].

${ }^{\mathrm{b}} \mathrm{CNWRA}$ also applied a dual-continuum model for separate TH analysis [7]. 
For simulation of rock-mechanical behavior, LBNL and UPC used elastic models, whereas CEA and CNWRA applied various elasto-plastic models. TM-induced permeability changes were modeled by three of the four teams: LBNL, UPC, and CNWRA. LBNL and CNWRA hypothesized that permeability is correlated to fracture aperture in orthogonal fracture sets, where the fracture aperture is subjected to fracture normal stress. UPC hypothesized that permeability is correlated to porosity, where porosity is controlled by volumetric strain.

All teams discretized the DST test area into twodimensional vertical cross sections through the center of the heated drift (Fig. 2). A two-dimensional geometry was deemed sufficient for predicting TM-induced rock displacements and permeability changes at selected monitoring boreholes in the vertical $x-z$ plane However, note that the temperature in the heated drift may be overestimated in a two-dimensional model since it neglects in situ three-dimensional out-of-plane heat loss, and heat loss through a bulkhead at the entrance of the heated drift. UPC, therefore, reduced the simulated heat power to be a constant value at $70 \%$ of the actual

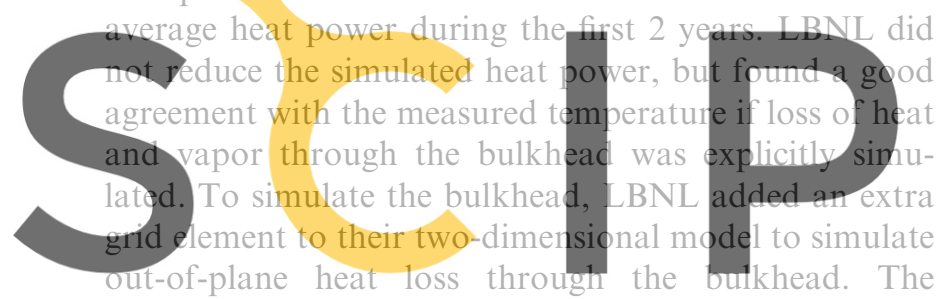
properties of the bulkhead element, corresponding to a

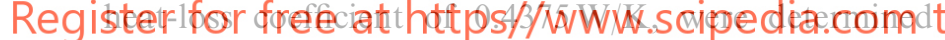
through model calibration against early temperature data.
Table 3 presents the model dimensions and boundary conditions used by each team and Table 4 presents initial conditions. Model dimensions, boundary, and initial conditions were assigned by each individual team based sufficiently far away from the drift to avoid impact of boundary effects on the simulated near-field THM responses. The lateral and vertical dimensions of the models $\left(L_{x}, L_{z 1}\right.$, and $\left.L_{z 2}\right)$ used by each team vary from a few hundred to thousand meters. The initial stress field varies somewhat among the research teams (Table 4). In general at Yucca Mountain, the maximum principal stress is vertical, with its magnitude approximated by the weight of the overburden rock mass. Considering the depth of the DST, ground surface topography, and densities of the overlying rock units, the vertical stress should be in the range of 4-6 MPa. The horizontal stresses are more uncertain because only a limited number of stress measurements have been conducted in the Tptpmn rock unit. The horizontal stresses at Yucca Mountain have been estimated to be about half of the vertical, but the ratio of horizontal to vertical stress could vary from 0.3 to 1.0 [25]. Recent stress measurements around the ESF confirm that

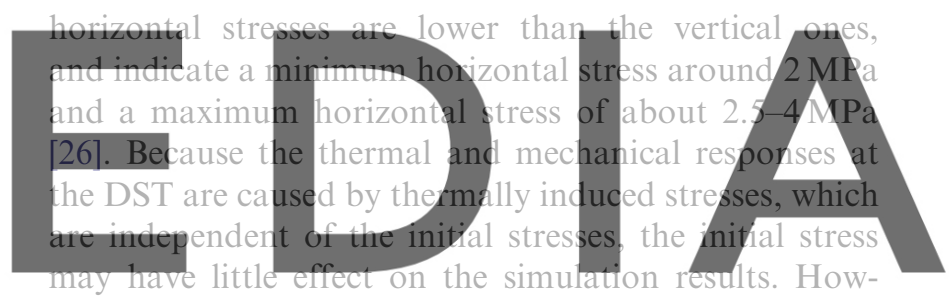

ever, as will be discussed in Section 6, the magnitude of

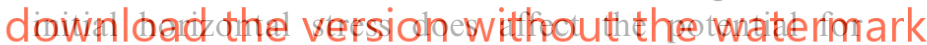
developing tensile failure and shear slip in regions of thermal stress relief away from the heated drift.

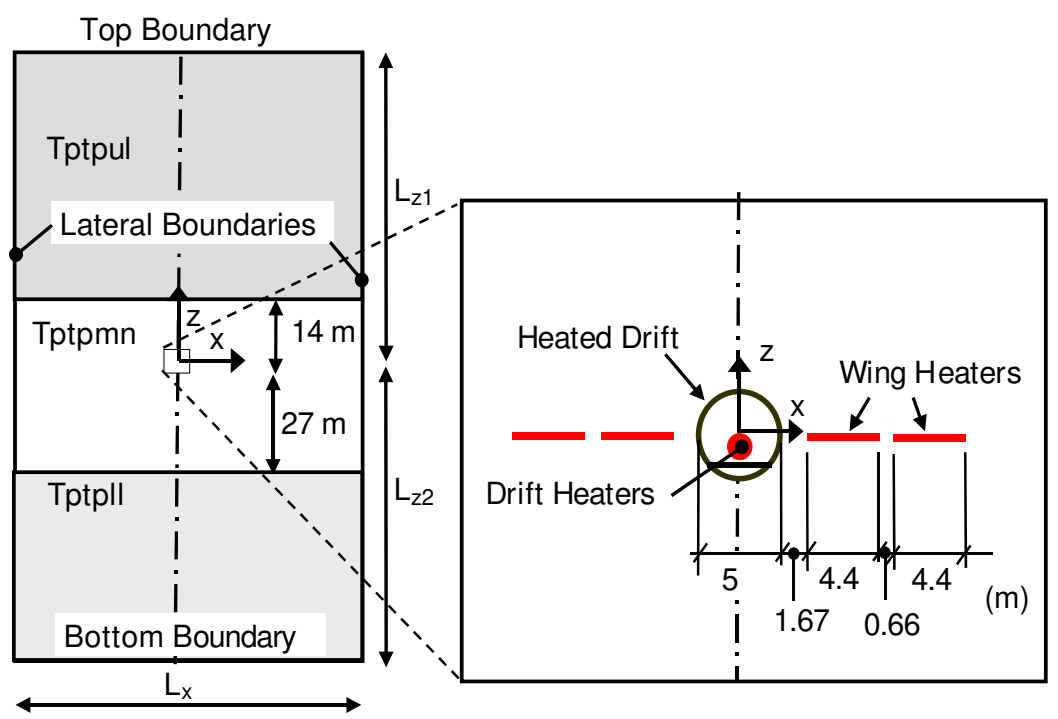

Fig. 2. Geometry of two-dimensional models for simulation of coupled THM processes at the DST. (See Table 2 for model dimensions and boundary conditions used by each research team.) 
Table 3

Model dimensions and boundary conditions (see also Fig. 2)

\begin{tabular}{|c|c|c|c|c|c|c|}
\hline \multirow[t]{2}{*}{ Team } & \multicolumn{3}{|c|}{ Model dimensions } & \multicolumn{3}{|l|}{ Boundary conditions } \\
\hline & $L_{x}(\mathrm{~m})$ & $L_{z 1}(\mathrm{~m})$ & $L_{z 2}(\mathrm{~m})$ & Top & Bottom & Lateral \\
\hline LBNL & 200 & 100 & 150 & $\begin{array}{l}T=22.8^{\circ} \mathrm{C} \\
\sigma_{z}=\sigma_{\mathrm{v}}=3.61 \mathrm{MPa} \\
P_{\mathrm{g}}=0.085 \mathrm{MPa} \\
S_{\mathrm{lm}}=0.70 \\
S_{\mathrm{lf}}=0.082\end{array}$ & $\begin{array}{l}T=28.0^{\circ} \mathrm{C} \\
P_{\mathrm{g}}=0.085 \mathrm{MPa} \\
S_{\mathrm{lm}}=0.92 \\
S_{\mathrm{lf}}=0.071\end{array}$ & $\begin{array}{l}\sigma_{x}=\sigma_{\mathrm{H}}=\sigma_{\mathrm{v}} 0.6=[3.61+2200 \times 9.81 \times(z-100)] \times 0.6 \mathrm{MPa} \\
q_{\mathrm{w} x}=0 \\
q_{\mathrm{t} x}=0\end{array}$ \\
\hline UPC & 180 & 100 & 150 & $\begin{array}{l}T=24^{\circ} \mathrm{C} \\
P_{\mathrm{g}}=0.1 \mathrm{MPa} \\
q_{\mathrm{l} z}=0.36 \mathrm{~mm} / \text { year } \\
\sigma_{z}=\sigma_{\mathrm{v}}=8 \mathrm{MPa}\end{array}$ & $\begin{array}{l}T=24^{\circ} \mathrm{C} \\
P_{\mathrm{g}}=0.1 \mathrm{MPa} \\
P_{1}=-0.3 \mathrm{MPa} \\
u_{z}=0\end{array}$ & $\begin{array}{l}T=24^{\circ} \mathrm{C} \\
P_{\mathrm{g}}=0.1 \mathrm{MPa} \\
q_{\mathrm{w} x}=0 \\
u_{x}=0\end{array}$ \\
\hline CEA & 570 & 150 & 150 & $\sigma_{z}=\sigma_{\mathrm{v}}=1.3 \mathrm{MPa}$ & $u_{z}=0$ & $u_{x}=0$ \\
\hline CNWRA & 1000 & 240 & 500 & $\sigma_{z}=\sigma_{\mathrm{v}}=0 \mathrm{MPa}($ ground $)$ & $u_{z}=0$ & $u_{x}=0$ \\
\hline
\end{tabular}

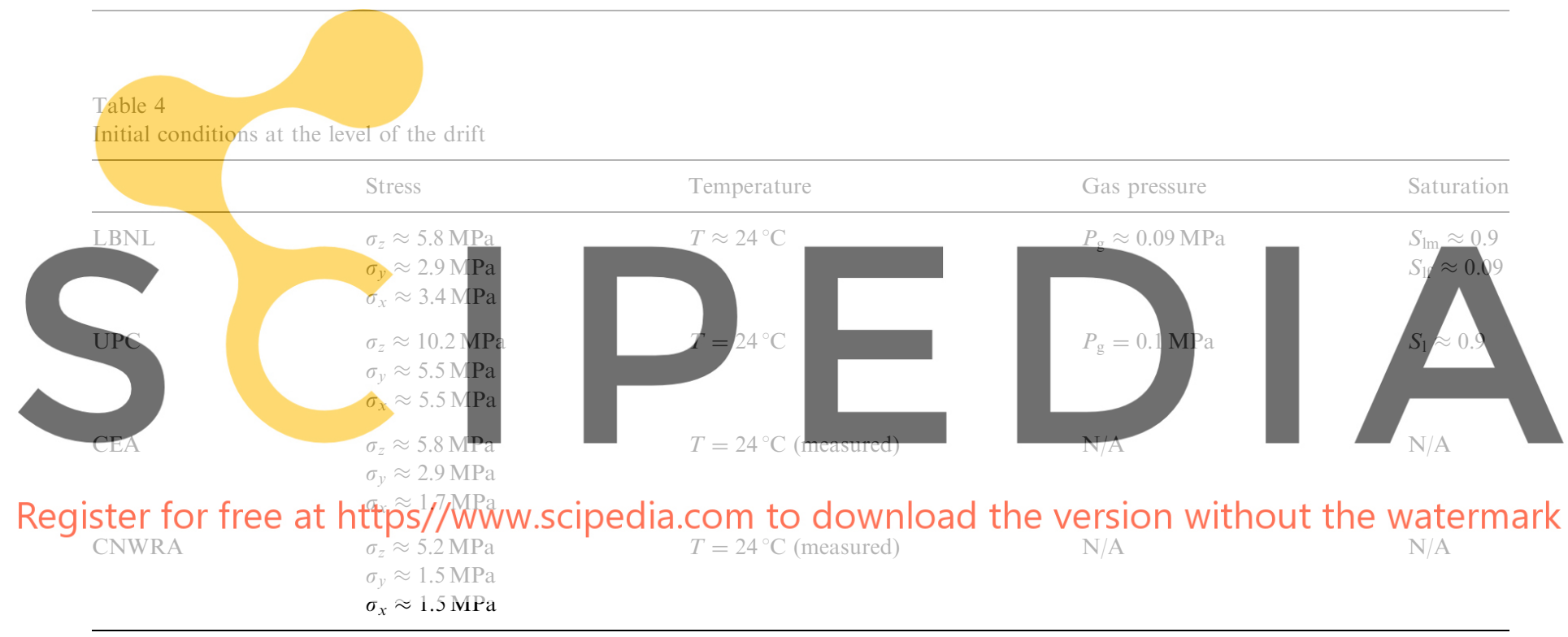

Table 5 presents material properties adopted by each research team. The respective research teams derived material properties suitable for their respective modeling approach using site data from Yucca Mountain project reports (e.g., [29] for mechanical properties). In Table 5, hydrologic and thermal properties are marked N/A for CEA and CNWRA, since these research teams did not calculate thermal and hydrological processes. The hydrologic properties used by LBNL include waterretention and relative-permeability functions representing fractured and matrix continua, whereas UPC uses equivalent continuum properties representing a composite effect of matrix and fractures. The rock-mechanical properties include rock-mass deformability and strength. The Young's modulus adopted for the fractured rock mass by LBNL and CNWRA is about $50 \%$ of the values of intact rock, whereas UPC and CEA used intact-rock values. Strength properties used in the elasto-plastic ubiquitous joint models used by CEA and CNWRA are also listed. However, the most important parameters for simulation of THM responses at the DST are coefficient of thermal expansion and parameters defining the relationship between fracture normal stress and permeability. LBNL, CNWRA, and CEA adopted temperature dependent thermal expansion coefficients representing values determined from intact core samples (Fig. 3). UPC used a constant value, which depending on the temperature is up to twice the values of thermal expansion adopted by the other teams.

The permeability changes at the DST were predicted by LBNL, CNWRA, and UPC, using individually derived stress-versus-permeability functions. LBNL derived a stress-versus-permeability function based on a conceptual model of highly fractured rock containing three orthogonal fracture sets (see the schematic cubic block model for LBNL in Fig. 4). Fracture 
Table 5

Material properties adopted for the predictive analyses presented in this paper ${ }^{\mathrm{a}}$

\begin{tabular}{|c|c|c|c|c|}
\hline Property & LBNL & UPC & CEA & CNWRA \\
\hline Permeability & $\begin{array}{l}k_{\mathrm{m}}=1.24 \times 10^{-17} \mathrm{~m}^{2} \\
k_{\mathrm{f}}=1.0 \times 10^{-13} \mathrm{~m}^{2}\end{array}$ & $k=1.0 \times 10^{-13} \mathrm{~m}^{2}$ & $\mathrm{~N} / \mathrm{A}$ & $\mathrm{N} / \mathrm{A}$ \\
\hline Porosity & $\begin{array}{l}\phi_{\mathrm{m}}=0.11 \\
\phi_{\mathrm{f}}=0.263 \times 10^{-3}\end{array}$ & $\phi=0.11$ & $\mathrm{~N} / \mathrm{A}$ & $\mathrm{N} / \mathrm{A}$ \\
\hline Parameters for water & $P_{0 \mathrm{~m}}=0.444 \mathrm{MPa}$ & $P_{0}=0.444 \mathrm{MPa}$ & $\mathrm{N} / \mathrm{A}$ & $\mathrm{N} / \mathrm{A}$ \\
\hline
\end{tabular}

retension and liquid relative

permeability for van

Genuchten-Mualem model

[27]

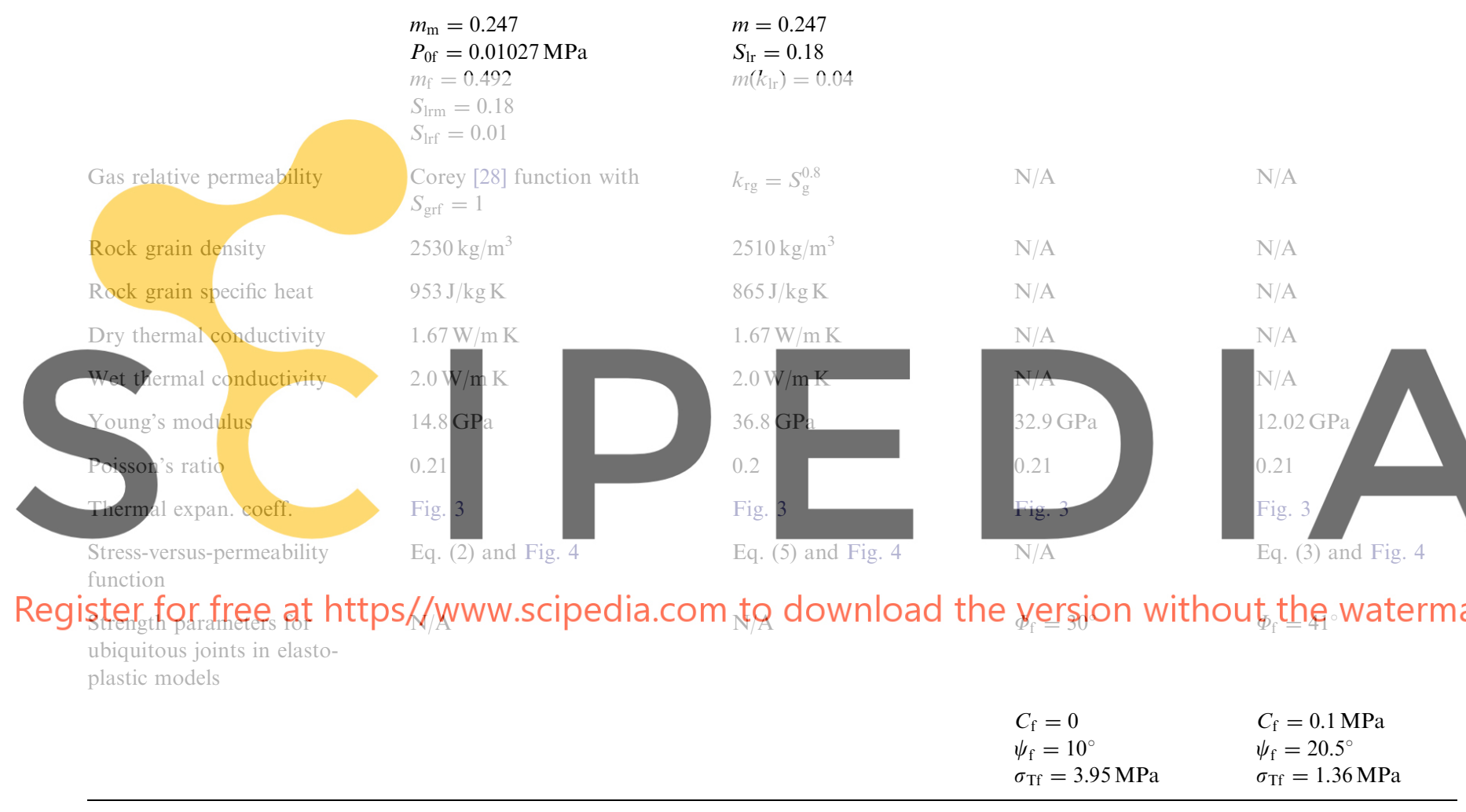

${ }^{\text {a }}$ Sensivity studies with variation of parameter values were also conducted by each research team.

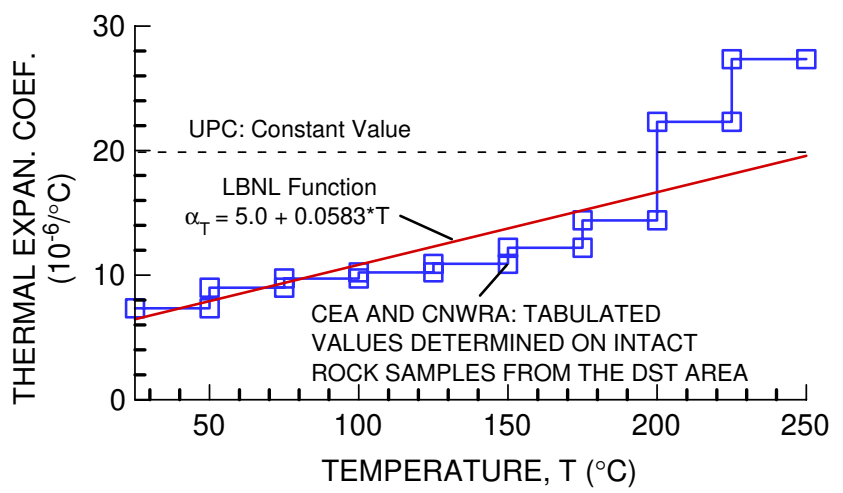

Fig. 3. Thermal expansion coefficient adopted by different research teams, with comparison to values determined on intact-rock samples from the DST test block. apertures for each set were calculated using an exponential function [3]

$b=b_{\mathrm{r}}+b_{\max } \exp \left(-a \sigma_{\mathrm{n}}\right)$,

where $b_{\mathrm{r}}$ is the residual aperture at high compressive normal stress $\sigma_{\mathrm{n}}$, and $b_{\max }$ and $a$ are empirical parameters that were determined by calibration against various field experiments at Yucca Mountain [30]. Applying a parallel plate flow model to Eq. (1), the permeability correction factor, $F_{k}$, in each fracture set is calculated according to [30]

$$
F_{k}=\left(\frac{b}{b_{\mathrm{i}}}\right)^{3}=\left(1+\frac{b_{\max }}{b_{\mathrm{i}}}\left[\exp \left(-a \sigma_{\mathrm{n}}\right)-\exp \left(-a \sigma_{\mathrm{ni}}\right)\right]\right)^{3},
$$




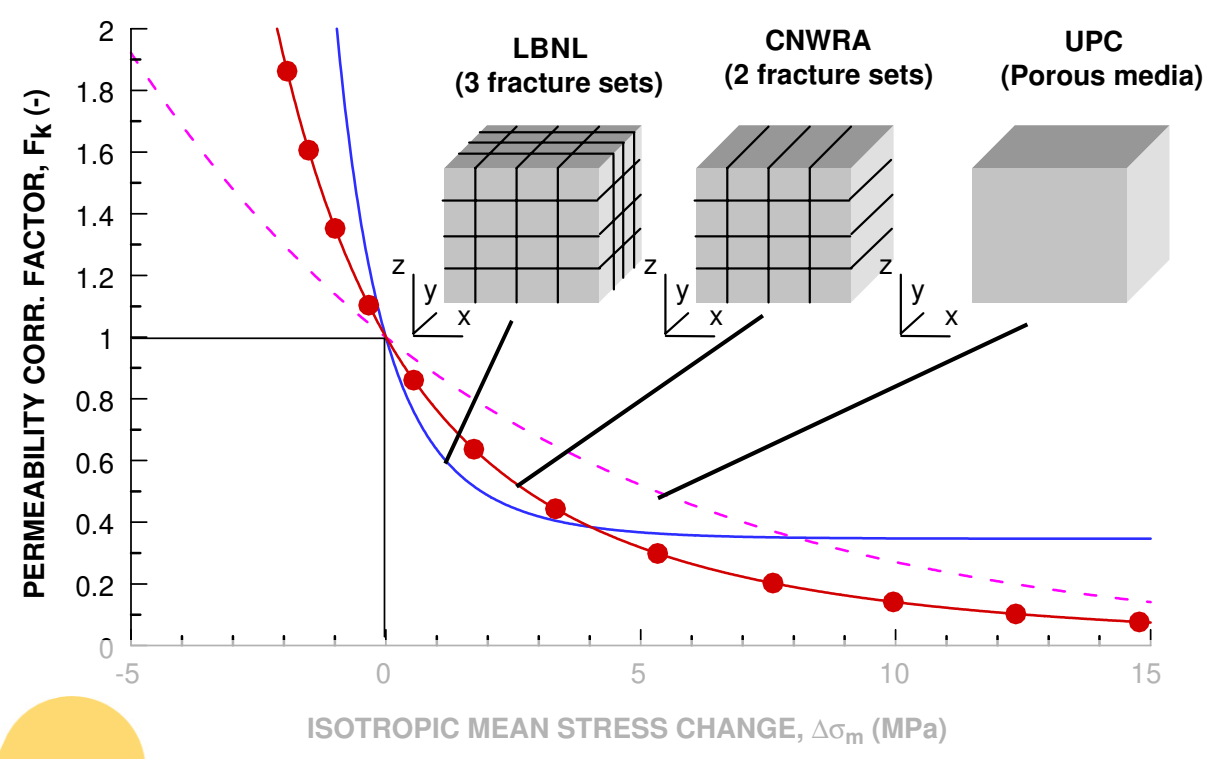

Fig. 4. Permeability correction factor $F_{k}=k / k_{\mathrm{i}}$ as a result of isotropic changes in stress for stress-versus-permeability models of LBNL, CNWRA, and UPC.

where $b_{\mathrm{i}}$ is the initial aperture and $\sigma_{\mathrm{ni}}$ is the initial normal stress across each fracture set. In the analysis

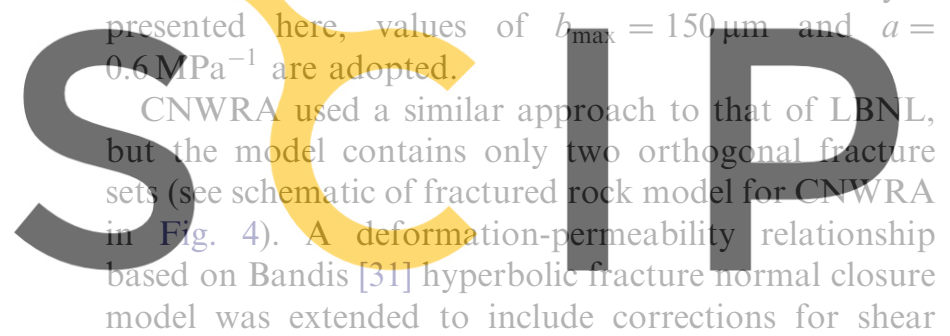

Registericiorcfreeeinatthttteps//www.scipedia.com to

$F_{k}=\left(\frac{b}{\bar{b}_{\mathrm{i}}}\right)^{3}=\left(\frac{d}{c\left(c \sigma_{\mathrm{n}}+1\right) b_{\mathrm{i}}}-\frac{e_{\mathrm{ftp}}+e_{\mathrm{fsp}} \tan \psi_{\mathrm{f}}}{\phi_{\mathrm{fi}}}\right)^{3}$

where $c$ is a constant that can be derived from initial values of normal stress and aperture, and $d$ is the reciprocal of initial fracture normal stiffness [10]. In Eq. (3), $e_{\mathrm{ftp}}$ and $e_{\mathrm{fsp}}$ are tensile and shear plastic strains, $\phi_{\mathrm{fi}}$ is initial fracture porosity, and $\psi_{\mathrm{f}}$ is the dilation angle. For the Tptpmn unit surrounding the DST, an initial normal stiffness of $201 \mathrm{GPa} / \mathrm{m}$ and an initial fracture porosity of 0.01 was adopted.

UPC applied an empirical permeability-versus-porosity relationship

$k=k_{\mathrm{i}} \exp \left(-\gamma\left(\phi_{\mathrm{i}}-\phi\right)\right)$,

where $k_{\mathrm{i}}$ and $\phi_{\mathrm{i}}$ are initial values of permeability and porosity, and $\gamma$ is an empirical constant [8]. The current porosity $\phi$ is calculated from the volumetric strain, corrected for thermal expansion of grains. For an elastic material, this corresponds to a stress-versus-permeability function controlled by changes in mean stress, $\Delta \sigma_{\mathrm{m}}$, as

$F_{k}=\exp \left(-A \Delta \sigma_{\mathrm{m}}\right)$ where $A$ can be derived from initial porosity, bulk modulus, and $\gamma$. For the results presented in this paper,

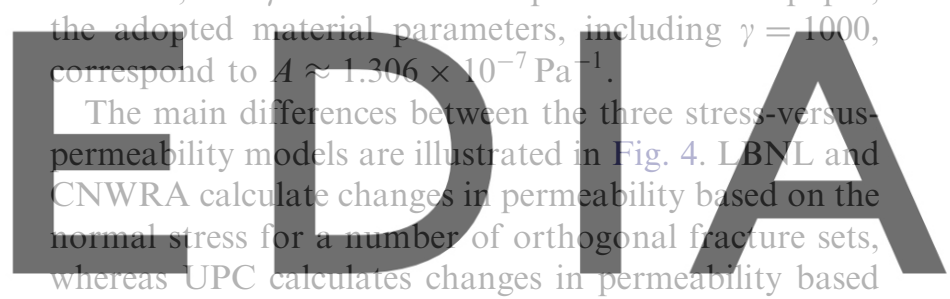

on changes in mean stress. Thus, changes calculated by

dbownload the Rersio pe withoonticthlepwaterpnark normal stress across different fracture sets, whereas UPC calculates isotropic changes in permeability controlled by changes in mean stress. Fig. 4 compares the stress-permeability functions of the three research teams for a special case of isotropic changes in stress. For an isotropic stress change, the various functions show some similarity, although there are differences in slope and residual permeability.

\section{Main THM responses during the heating test}

A solid understanding of the main coupled THM responses has been gained through extensive field monitoring at the DST and from the four independent numerical analyses reported in this paper. The coupled THM responses at the DST are driven by changes in rock temperature during the 4-year heating period and the following natural cooling. The rock-mass temperature was about $24^{\circ} \mathrm{C}$ prior to heat initiation, and the liquid water saturation in the rock matrix was about $90 \%$. After the heaters were turned on, the temperature at the drift wall rose to the boiling point (about $96{ }^{\circ} \mathrm{C}$ ) within three months (Fig. 5). After a short pause in the 


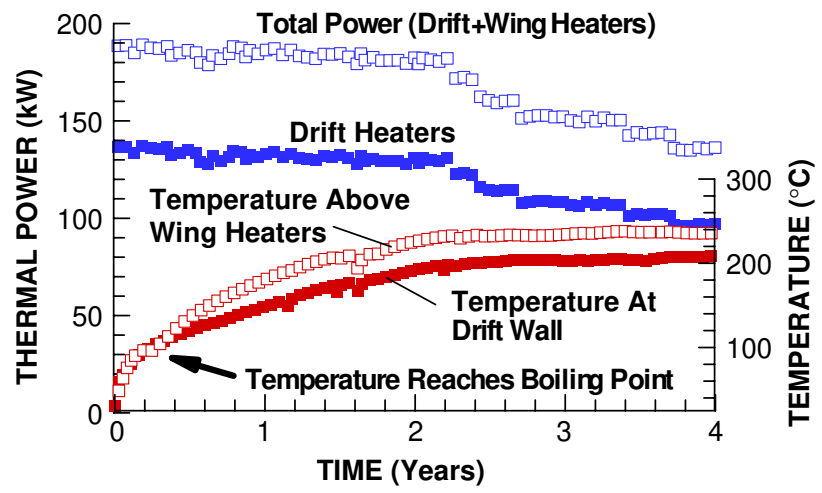

Fig. 5. Thermal power and measured temperature at the drift wall and at a monitoring point located above the wing heater at a horizontal distance of $10 \mathrm{~m}$ from the center of the drift.

temperature rise, while liquid water in the rock matrix and reflux water in the fractures was vaporized, the temperature continued to rise at a slower rate. During the test, the thermal input was manually reduced by $10 \%$ a few times to maintain the drift-wall temperature at about $200{ }^{\circ} \mathrm{C}$ (Fig. 5). Nevertheless, high temperature at the DST induces strongly coupled THM processes.

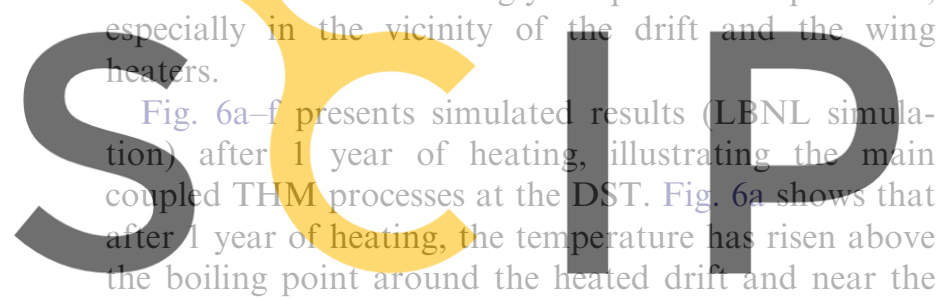
wing heaters. High temperature induces evaporation of

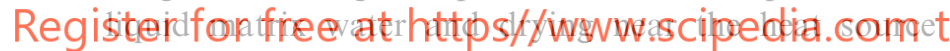
(Fig. 6b and c, dryout zone). The evaporated water is transported as vapor away from the heat source in the permeable fracture system toward cooler regions, where it is condensed to liquid water (Fig. 6b, dark zone). As a result, a dryout zone is created near the heat source, and a condensation zone moves progressively away from the heat source. At the same time, high temperature gives rise to thermal expansion of the rock matrix, with associated TM-induced displacements and stresses (Fig. 6d and e). At 1 year, the maximum calculated displacement is greater than $4 \mathrm{~mm}$ at a distance of 5-10 $\mathrm{m}$ above drift (Fig. 6d). Near the heat source, the horizontal compressive stress increases strongly, with a maximum increase at the drift wall and near the wing heaters (Fig. 6e). Such an increase in compressive stress reduces fracture apertures leading to a decrease in fracture permeability. Away from the heat source, however, the horizontal stress decreases slightly (Fig. 6e, top). This decrease in horizontal stress unloads pre-existing vertical fractures that open to greater apertures, leading to an increase in air permeability in this area.

Fig. 6f presents the calculated THM-induced changes in air permeability in the fracture system. The changes air permeability is plotted in Fig. 6f since the numerical simulation results should be compared with changes in air permeability measured through air-injection tests. Changes in air permeability are caused by the combined effect of $\mathrm{TH}$-induced changes in fracture moisture content shown in Fig. 6b and TM-induced changes in fracture aperture shown in Fig. 6e. Near the heat source, permeability decreases mainly because of fracture closure, but is also affected by $\mathrm{TH}$-induced wetting and drying. Away from the heat source, a zone of increased permeability has developed as a result of the opening of vertical fractures (Fig. 6f, near borehole section 74:4). The analyses by LBNL and CNWRA indicate that fracture closure/opening by changes in stress normal to fractures is the dominant mechanism for intrinsic permeability changes at the DST $[9,10]$. This indicates that permeability changes caused by shear slip are small compared to changes by normal stress. However, both CNWRA and CEA simulation results indicate that shear slip can be initiated along preexisting fractures after a few years of heating, especially around the drift and in the zone of stress reduction about $15 \mathrm{~m}$ above the drift (see zone of horizontal stress

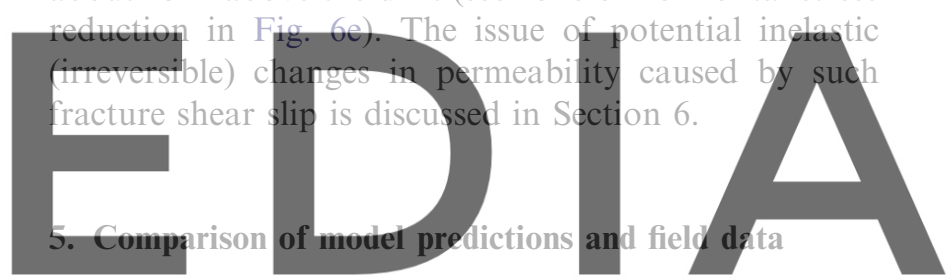

This section provides comparison of simulated and

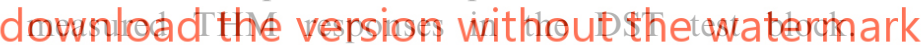
Simulated and measured rock temperatures are first compared in Section 5.1, since temperature change is the driving force behind the coupled THM processes at the DST. Sections 5.2 and 5.3 provide comparison of simulated and measured displacements and changes in air permeability, respectively.

\subsection{Rock temperature}

Fig. 7 shows simulated and measured temperature evolution at the drift wall, and Fig. 8 presents simulated and measured temperature profiles along a vertical borehole emanating from the crown of the heated drift. The figures show an excellent agreement between simulated and measured temperature for LBNL and a reasonably good agreement for UPC. The difference in simulated temperature between LBNL and UPC can be explained by their respective approaches of simulating out-of-plane and bulkhead heat loss. As described in Section 3.3, UPC reduced the heat power input to their two-dimensional model simulation to about $70 \%$ of the actual heat power. (The actual heat power per meter drift applied to two-dimensional models is the total power shown in Fig. 5, divided by the heated length of 

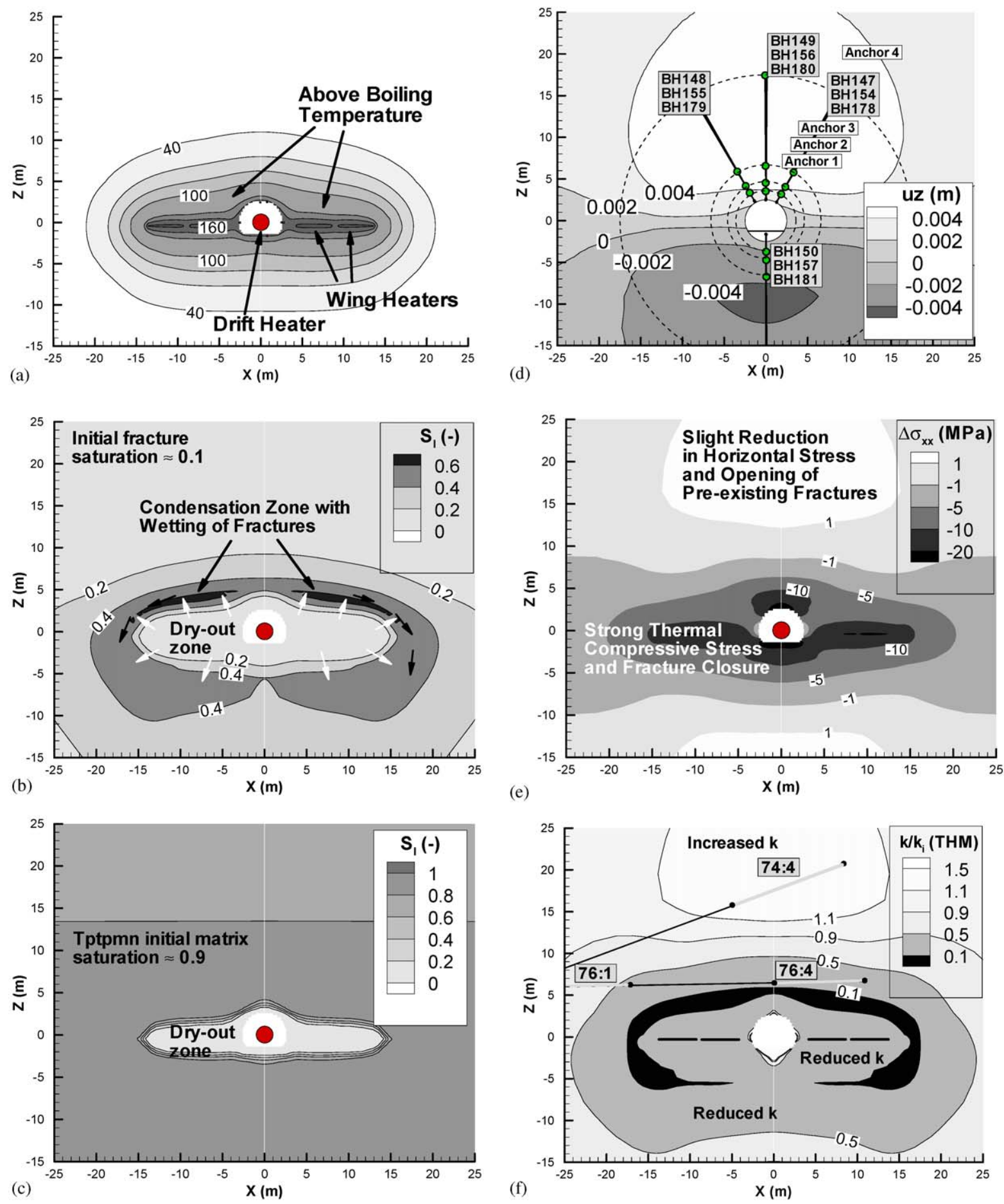

Fig. 6. Calculated distribution of (a) temperature, (b) liquid saturation in fractures, (c) liquid saturation in rock matrix, (d) thermally induced vertical displacement, (e) thermally induced horizontal stress, and (f) THM-induced changes in fracture permeability after 1 year of heating (LBNL simulation).

the drift, which is $47.5 \mathrm{~m}$.) Although this approach results in an overall reasonable agreement with measured temperature, it overestimates the heat loss during the first year and underestimates the heat loss toward the end of the heating period. The excellent agreement achieved by LBNL between simulated and measured temperature throughout the 4-year heating period shows that the explicit simulation of the bulkhead with an additional element provides an accurate representation of heat loss. It correctly simulates heat loss as being proportional to the thermal gradient across the bulkhead, rather than being proportional to the heating power. CEA and CNWRA are not included in Figs. 7 and 8 , since these research teams did not perform a 


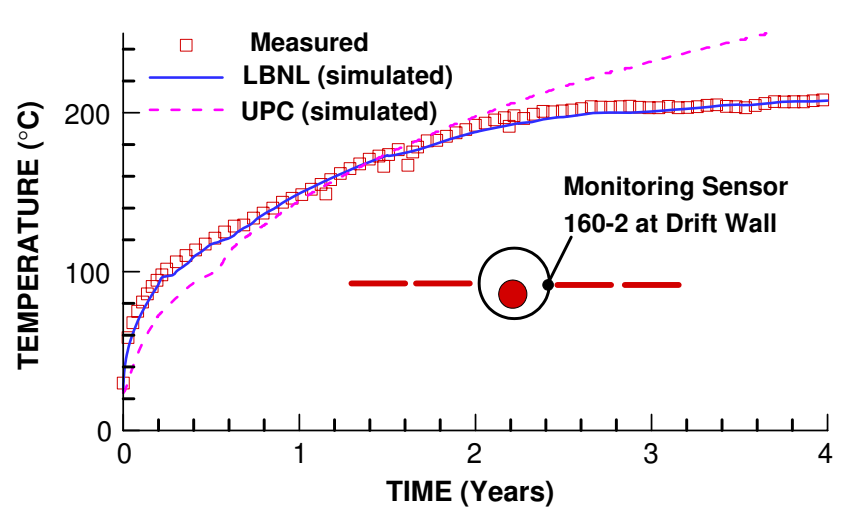

Fig. 7. Comparison of evolution of simulated and measured temperature at the drift wall.

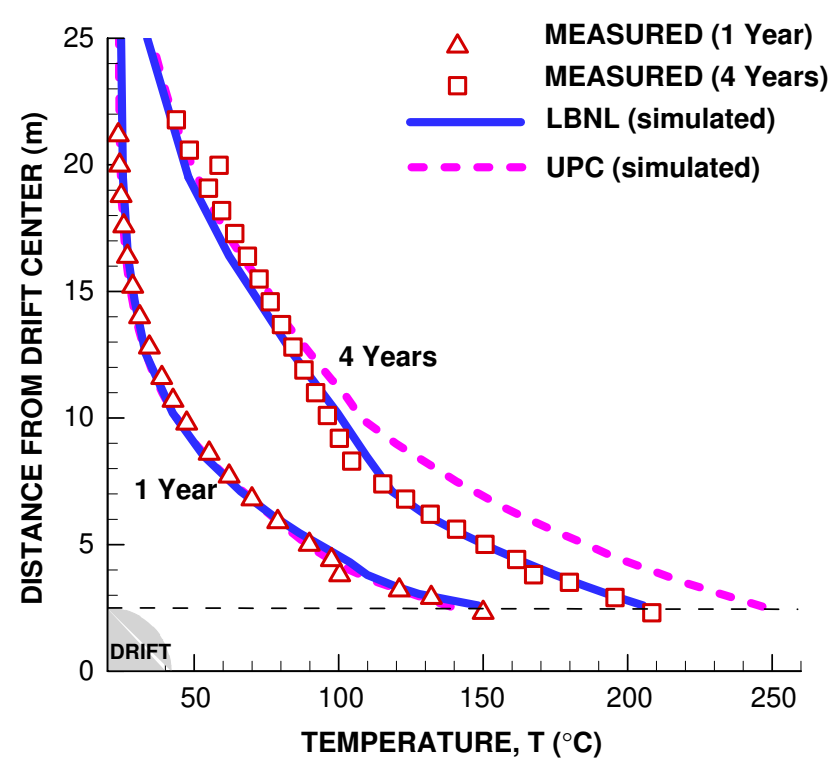

Fig. 8. Measured and simulated temperature profile along borehole 158 extending upward from the crown of the drift.

temperature simulation, but imported the measured temperature into their models (described in Section 3.3). The temperature distributions in the CEA and CNWRA models are represented by the measured data in Figs. 7 and 8 .

\subsection{Rock displacements}

The research teams predicted the time evolution of rock-mass incremental displacements along extensometer boreholes (shown in Fig. 6d) for a borehole array located at $y=21 \mathrm{~m}$ (i.e., close to the middle of the $50 \mathrm{~m}$ long heated drift). As mentioned in Section 2, four extensometer anchors are attached to the borehole wall at a distance of about 1, 2, 4, and $15 \mathrm{~m}$ from the drift wall, and the displacements of each anchor, relative to the drift wall, are continuously monitored. Sensitivity analyses showed that displacement magnitudes are mainly dependent on the coefficient of thermal expansion, and to a lesser extent on the rock-mass deformation modulus. As described in Section 3.3, the thermal expansion coefficients adopted by LBNL, CEA, and CNWRA are similar with intact-rock values determined on core samples. The UPC team used a thermal expansion coefficient that on average was twice the value of any other team and consequently calculated displacement values about twice as large. Because the thermal expansion coefficient adopted by the UPC team is twice as high as any other team (and twice as high as the thermal expansion of intact rock), an intercomparison is not meaningful, and therefore, UPC's displacement result is excluded in the following detailed comparison.

Fig. 9 shows a comparison between simulated and measured results for extensometer boreholes 155 and 156 , the two extensometers having the most complete set of measured data (see location of these boreholes in Fig. 6d). In general, the displacements predicted by LBNL, CEA, and CNWRA are consistent, with larger incremental displacement for anchors located farther away from the drift wall. As long as the simulated mechanical responses are elastic, the simulated displacements along borehole 155 are very close to those measured for anchors 3 and 4, whereas the displacement for anchors 1 and 2 is underpredicted (Fig. 9a-d). The CEA's elasto-plastic ubiquitous joint model overpredicts displacements in borehole 155, especially in anchors 3 and 4 (Fig. 9c and d). The result for borehole 156 shows excellent predictions of displacement in anchor 3, whereas the displacements in anchors 2 and 4 are generally underpredicted. Most notably, the CEA's elasto-plastic ubiquitous joint model provides the best prediction for anchor 4 of borehole 156, both in trends and magnitude. This indicates that for anchor 4 the local displacement is affected by inelastic rock-mass responses such as shear slip along fractures.

Fig. 10 presents a comparison of calculated and measured displacements at the end of the heating period as a function of distance from the borehole collar (drift wall). In Fig. 10, the shaded area represents the range of the field data available from all inclined boreholes (BH147, 148, 154, 155, 178, 179 shown in Fig. 6d), and all upper vertical boreholes (BH 149, 156, 180 shown in Fig. 6d) located in three borehole arrays at $y=41.1$, 21.0 , and $13.7 \mathrm{~m}$. All these arrays are located within the axial extension of the heated drift, with the one at $41.1 \mathrm{~m}$ being farthest out, located about $4.6 \mathrm{~m}$ from the end of the heated drift. In general, Fig. 10 shows that the calculated displacements are generally within the range of the field data, except in areas close to the drift wall. Near the drift wall, there appears to be an additional shift in the displacement field. The CEA's elasto-plastic ubiquitous joint model overpredicts the displacements 

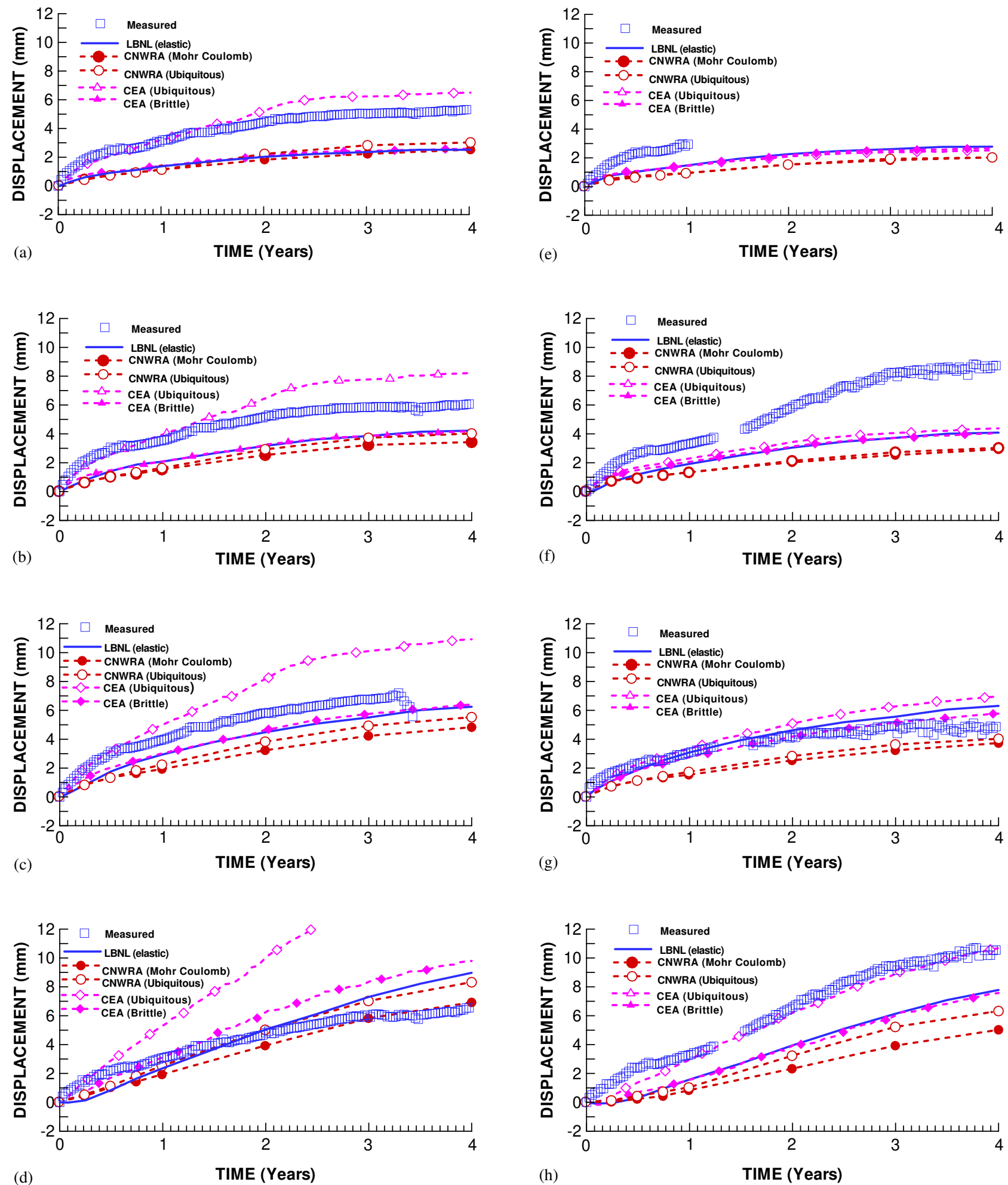

Fig. 9. Measured and simulated displacements in extensometer anchors 1, 2, 3, and 4 in borehole 155 and 156. (a) 155:1; (b) 155:2; (c) 155:3; (d) $155: 4$; (e) $156: 1$; (f) $156: 2$; (g) $156: 3$; (h) $156: 4$.

in the $60^{\circ}$ inclined boreholes possibly because of an overprediction of near-wall inelastic deformation (Fig. 10a). The CNWRA model underpredicts the displacements in upper vertical boreholes (Fig. 10b).

\subsection{Fracture permeability}

The research teams predicted the evolution of fracture permeability at specific borehole locations where 

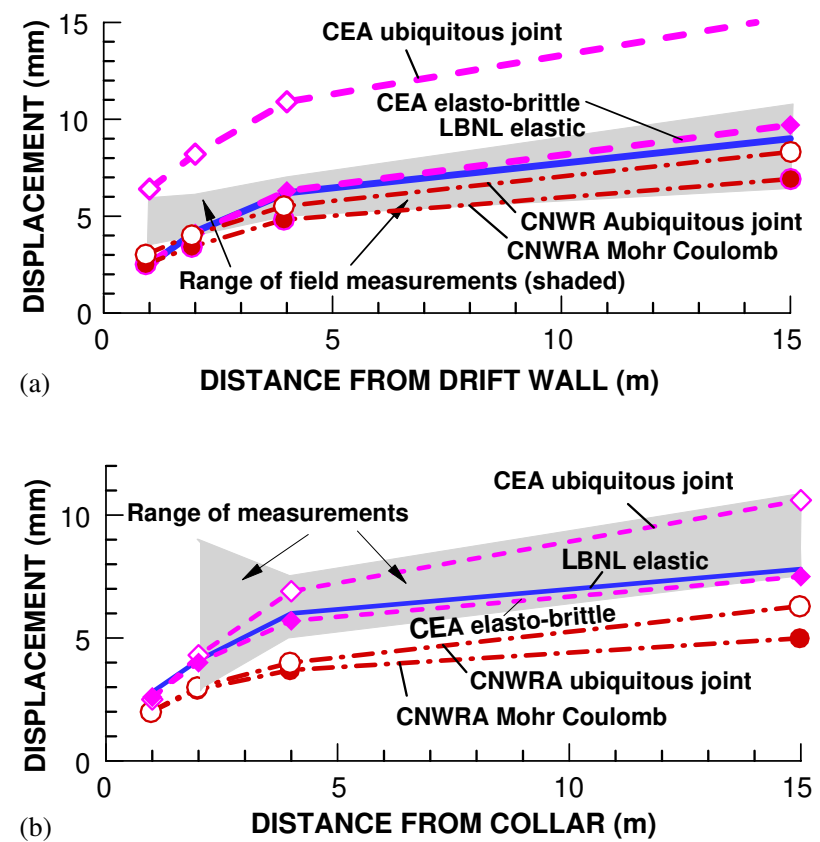

Fig. 10. Comparison of model predictions and ranges of measured displacements after 4 years of heating. (a) Inclined boreholes; (b) Upper vertical boreholes.

air-injection tests are conducted at regular time intervals of about three months. In this paper, three packed-off boreholes sections-denoted as 76:4, 74:4, and 76:1, located in a borehole array at $y=30.2 \mathrm{~m}$ - are selected for a detailed comparison of simulated and measured evolution of fracture permeability (see locations of packed-off sections in Fig. 6f). These borehole sections were selected for comparison because they represent characteristic responses of fracture permeability at various locations around the heated drift: near the heat source (Section 76:4), far above the heat source (Section 74:4), and far on the side of the heat source (Section 76:1).

As discussed in Section 4, changes in air permeability are caused by the combined effect of TH-induced changes in fracture moisture content (Fig. 6b) and TM-induced changes in fracture aperture (Fig. 6e). THinduced changes in fracture moisture content cannot be directly measured, since the moisture in the fracture system is only a small fraction of the total moisture content of the fracture-matrix system. The drying in the matrix at the DST is monitored by geophysical methods that include ground penetrating radar, electric resistivity tomography, and neutron logs [14]. A comparison of those geophysical data with the results by LBNL and UPC indicates that the extent of the dryout zone is controlled by the boiling temperature isotherm, and is well captured in the numerical results. TM-induced changes in fracture permeability are controlled by thermal stress and the adopted stress-versus-permeability relationship. The calculated thermal stress is in turn a function of calculated temperature changes, the thermal expansion coefficient, and the modulus of rock-mass deformation. A direct comparison of the thermal stresses calculated by different teams was not performed. However, based on the thermal expansion coefficient and Young's modulus adopted by each team (Table 5), the thermal stress for UPC should be higher by roughly a factor of four compared to LBNL and CNWRA. Such difference in the calculated thermal stress impacts the time evolution of TM-induced changes in fracture permeability.

Sensitivity studies by LBNL, UPC, and CNWRA show that the stress-versus-permeability relationship is the most important parameter for predicting the evolution of the fracture permeability. Obviously, if a more sensitive relationship between stress and permeability is adopted in the analysis, stronger changes in permeability will be predicted. It was also shown, by LBNL and CNWRA, that the permeability changes in vertical and horizontal fractures can be very different in some areas around the drift. In general, the permeability changes more in vertical fractures than in horizontal, because vertical fractures are exposed to greater TM-induced stress changes.

Fig. 11 presents a comparison of measured and simulated fracture permeability (airflow permeability in the fracture system) for the three borehole sections. In this comparison, the mean permeability calculated by each research team is compared to the measured results. For LBNL and CNWRA, the mean permeability correction factor is represented by the geometric mean $F_{k}$ of permeability correction factors for directional permeability change factors

$F_{k}=\sqrt[3]{F_{k x} F_{k y} F_{k z}}$

where $F_{k x}, F_{k y}$, and $F_{k z}$ are permeability correction factors for permeability in $x-, y$-, and $z$-direction, respectively. With some exceptions, the simulated results are in good agreement with the measured results for all teams in Section 76:4 (near heat source) and 76:1 (on the side of the heat source), whereas only LBNL has a good agreement with the results at $74: 4$.

At 76:4, all teams correctly predict a decrease in air permeability during the first 2 years. This decrease in air permeability is the combined effect of TM-induced fracture closure and $\mathrm{TH}$-induced condensation in the fracture system. The analyses by LBNL and CNWRA show that TM-induced decrease in intrinsic permeability occur both in vertical and horizontal fractures. Therefore, the measured decrease is also well captured using the mean stress-based model by UPC. After about 2 years of heating, the measured air permeability appears to recover somewhat. LBNL and UPC capture this partial recovery of air permeability as a result of drying of the fracture system around borehole 76:4. CNWRA, on the other hand, does not capture such recovery 

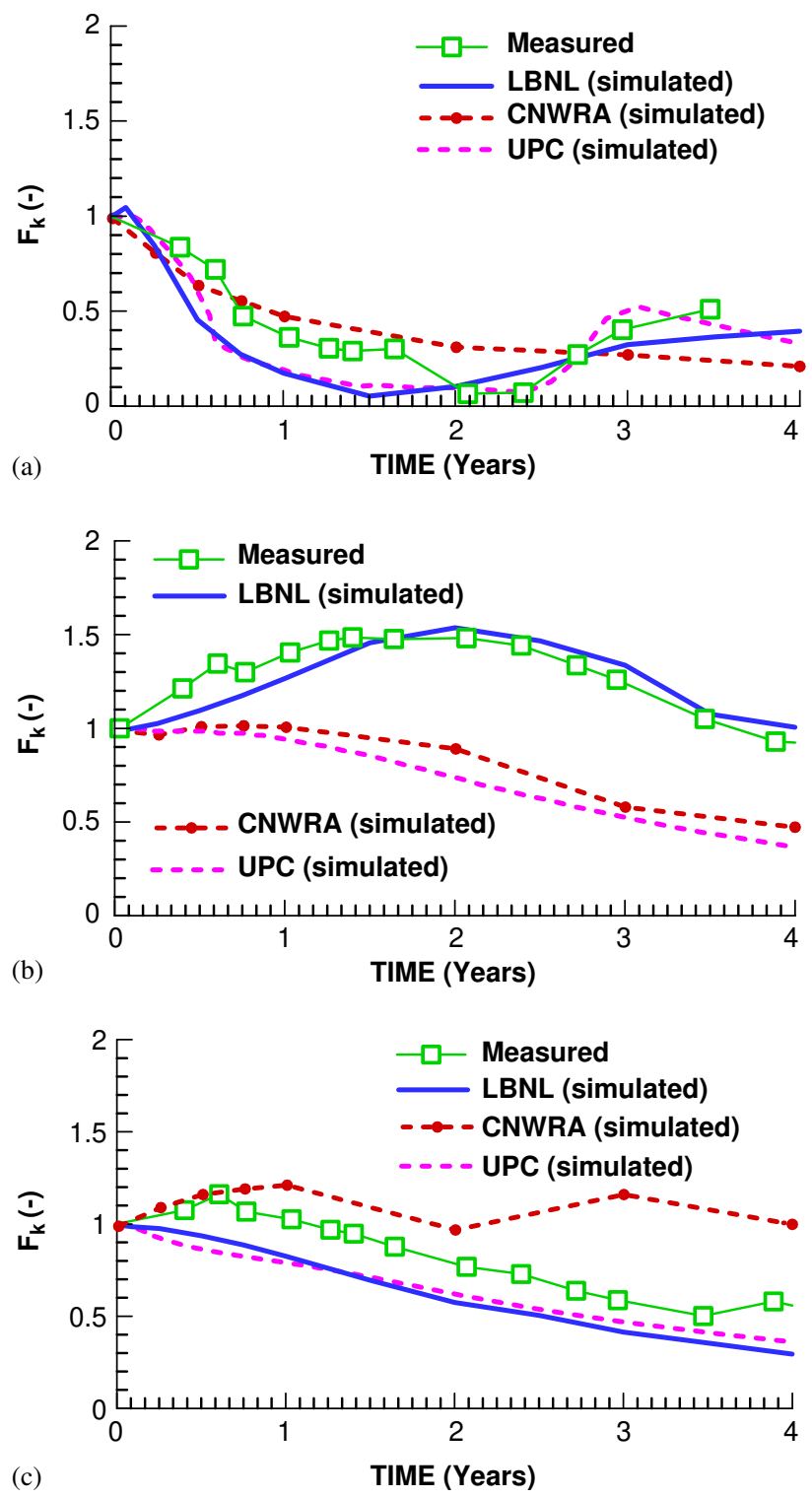

Fig. 11. Measured and simulated evolution of permeability correction factor $\left(F_{k}=k / k_{\mathrm{i}}\right)$ for three different borehole sections. (a) Section 76:4; (b) Section 74:4; (c) Section 76:1.

because they did not account for TH-induced changes in moisture content within their analysis.

At 76:1, LBNL and UPC predict a gradual reduction in air permeability with time. CNWRA predicted a slight increase during the first year, and thereafter a slight fluctuation until the end of the heating. The simulated results are roughly similar to the measured, with better agreement achieved by LBNL and UPC. The analyses by CNWRA and LBNL showed that at this location the intrinsic permeability of vertical fractures decreases, while the intrinsic permeability of horizontal fractures slightly increases. In the field, the net effect is a slight decrease in air permeability.
For Section 74:4, measured air permeability increases during the first 2 years and then gradually decreases. Only LBNL correctly simulates the magnitude of permeability increase during the first 2 years. The LBNL and CNWRA analyses showed that at $74: 4$, increase in permeability can be explained by a reduction in horizontal stress that tends to increase the aperture of vertical fractures. In LBNL's simulation, the effect of aperture increase in vertical fractures is sufficiently large to induce a net increase in mean permeability. In CNWRA's simulation, on the other hand, an increase in permeability in the vertical fractures was completely offset by a decrease in permeability in horizontal fractures. As a result, the simulated mean permeability did not match with measured results in 74:4. However, the measured permeability changes closely match CNWRA's calculated changes in permeability of the vertical fracture set. This is not unreasonable, considering that fractures oriented perpendicular to the borehole (i.e., subvertical fractures) may be the dominant conduits during the air-injection permeability testing. On the other hand, the UPC results indicate that a good match to measured data in $74: 4$ can probably not be achieved with a mean stress-based stress-versus-permeability function. Generally, the mean stress increases throughout the DST test block during heating and therefore cannot result in an increase in permeability such as measured in 74:4. Thus, a stress-versus-permeability function controlled by changes in fracture normal stress is essential for matching the observed permeability increase in Section 74:4.

The importance of the stress-versus-permeability function for predicting THM-induced changes in permeability at the DST is further illustrated in Fig. 12. The figure shows a comparison of TM-induced changes in intrinsic permeability (i.e., excluding $\mathrm{TH}-$ induced changes for LBNL and UPC) at borehole 76:4. The differences between calculated TM-induced permeability correction factors in Fig. 12 roughly correspond

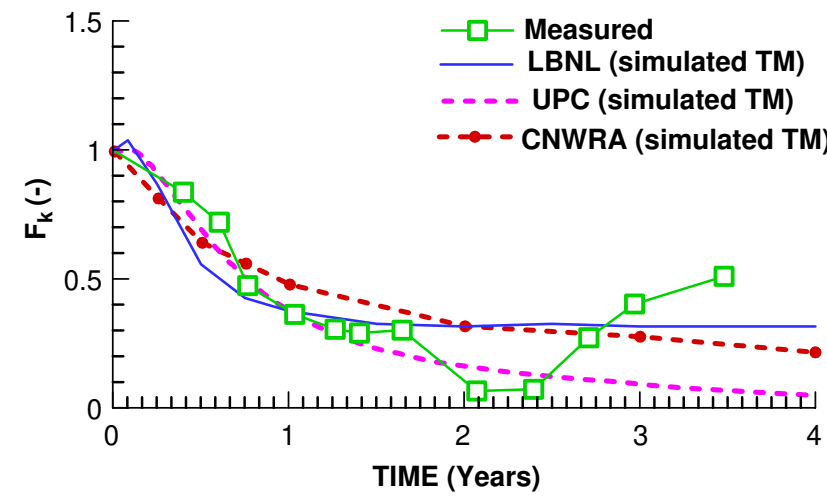

Fig. 12. Measured and simulated evolution of TM-induced permeability correction factor $\left(F_{k}=k / k_{\mathrm{i}}\right)$ at $76: 4$. 
to differences in each team's relationship between stress and permeability under isotropic stress change, shown in Fig. 4. For example, LBNL has the greater residual permeability, leading to a slightly higher permeability at the end of the heating phase in Fig. 12. The strongest reduction in TM-induced changes in permeability, calculated by UPC at the end of the heating, can be explained by the differences in the high stress region of stress-versus-permeability functions shown in Fig. 4, and by the fact that UPC calculated a much higher thermal stress.

\section{Discussion on irreversible changes}

For the performance assessment of a nuclear waste repository, long-term effects of relatively short-term coupled THM processes may be most relevant. Potential long-term effects of coupled THM processes are irreversible changes in hydrological properties remaining after temperature decay and thermal stress relief. Irreversible changes in fracture permeability could occur as a result of fracture shear dilation or crushing of fracture surface asperities during peak thermal stress. For example, if shear strength of fractures are exceeded, fractures may shear under dilation, leading to a permanent increase in fracture aperture and thereby an irreversible increase in fracture permeability. As discussed in Section 5, comparison of simulated and measured displacements indicates that some local displacements are affected by inelastic rock-mass responses such as shear slip along fractures. For example, the displacement for anchor 4 of borehole 156 was best matched using an elasto-plastic ubiquitous joint model rather than an elastic model. Moreover, CNWRA and CEA found that inelastic mechanical responses may occur, in some cases near the drift wall and in some cases away from the drift wall, in the zone of stress reduction about $15 \mathrm{~m}$ above the heated drift. The inelastic mechanical responses in this zone occurred because the in situ horizontal stress was reduced to zero. Thus, pre-existing vertical fractures were completely unloaded, resulting in a loss of fracture shear strength and associated fracture shear slip.

The question for the performance of a nuclear waste repository is how strongly permeability may change as a result of these inelastic deformations, and further, how large the irreversible changes in permeability may be? CNWRA calculated changes in permeability caused by the shear slip (represented by plastic shear strain in Eq. (3)) and found that these permeability changes would be relatively small. CNWRA concluded that permeability changes around the heated drift are dominated by changes in fracture aperture caused by the changes in normal stress across fractures [10]. This conclusion is also supported by the results of the LBNL team, which found good agreement between simulated and measured permeability changes using an elastic (reversible) model. Moreover, from air-permeability measurements in 46 borehole sections around the DST, there are no widespread increases in permeability that could indicate significant shear slip dilation. The measurements show that TM-induced changes in intrinsic permeability at the DST are within one order of magnitude, with the strongest changes occurring as a decrease in permeability at maximum thermal stress at the end of the heating period. Current trends in measured data, 2 years into the cooling phase, indicate that permeability recovers toward the initial preheating permeability. This indicates that most TM-induced changes in intrinsic permeability at the DST are likely to be reversible.

\section{Conclusions}

This paper presents analyses of the coupled THM processes at the Yucca Mountain DST by four research teams using four different numerical models. The generally good agreement between simulated and measured temperature, displacement, and changes in air permeability shows that the numerical models and underlying conceptual models have captured the coupled THM processes at the DST. From the analyses and discussions presented in this paper, the following specific conclusions can be drawn:

- A continuum model approach is appropriate for simulating relevant coupled THM processes at the DST.

- TM-induced rock deformations are generally well simulated using an elastic model, although some individual displacements appear to be better captured using an elasto-plastic model.

- The highest potential for inelastic deformation in the form of fracture shear slip occurs near the drift wall and in a zone of thermal stress decrease located more than $15 \mathrm{~m}$ above the heated drift.

- Fracture closure/opening caused by change in normal stress across fractures is the dominant mechanism for TM-induced changes in intrinsic fracture permeability, whereas fracture shear dilation appears to be less significant at the DST.

- TM-induced changes in permeability at the DST, which are within one order of magnitude, are likely to be mostly reversible.

\section{Acknowledgements}

The paper was prepared through financial support by: The Director, Office of Civilian Radioactive Waste 
Management, US Department of Energy, through Memorandum Purchase Order QA-B004220RB3X between Bechtel SAIC Company, LLC and the Ernest Orlando Lawrence Berkeley National Laboratory (Berkeley Lab), provided to Berkeley Lab through the US Department of Energy Contract No. DE-AC0376SF00098; the ENRESA (Empresa Nacional de Residuos, S.A.); the IRSN (Institut de Radioprotection et de Sûreté Nucléaire).

\section{References}

[1] Verpeaux P, Millard A, Charras T, Combescure A. A modern approach of large computer codes for structural analysis. Proceedings of the SmiRT conference, Los Angeles, USA, 1989.

[2] Itasca Consulting Group. FLAC - fast Lagrangian analysis of continua, version 4.0. Minneapolis, MN: Itasca Consulting Group Inc.; 2000.

[3] Rutqvist J, Wu YS, Tsang CF, Bodvarsson G. A modeling approach for analysis of coupled multiphase fluid flow, heat transfer, and deformation in fractured porous rock. Int J Rock Mech Min Sci 2002;39:429-42.

[4] Rutqvist J, Tsang CF. TOUGH-FLAC: a numerical simulator for analysis of coupled thermal-hydrologic-mechanical processes in fractured and porous geological media under multi-phase flow conditions. Proceedings of the TOUGH symposium 2003. Berkeley: Lawrence Berkeley National Laboratory; May 12-14, 2003.

[5] Olivella S, Gens A, Carrera J, Alonso EE. Numerical formulation for a simulator (CODE_BRIGHT) for the coupled analysis of saline media. Eng Computations 1995;13:87-112.

[6] Datta R, Barr D, Boyle W. Measuring thermal, hydrological, mechanical, and chemical responses in the Yucca Mountain Drift Scale Test. In: Stephansson O, Hudson JA, Jing L, editors. Coupled $\mathrm{T}-\mathrm{H}-\mathrm{M}-\mathrm{C}$ processes in geo-systems: fundamentals, modelling, experiments and applications. Oxford: Elsevier GeoEngineering Book Series; 2004. p. 155-60.

[7] Millard A, Rutqvist J. Comparative analyses of predicted and measured displacements during the heating phase of the Yucca Mountain Drift Scale Test. In: Stephansson O, Hudson JA, Jing $\mathrm{L}$, editors. Coupled $\mathrm{T}-\mathrm{H}-\mathrm{M}-\mathrm{C}$ processes in geo-systems: fundamentals, modelling, experiments and applications. Oxford: Elsevier Geo-Engineering Book Series; 2004. p. 187-92.

[8] Olivella S, Gens A, Gonzalez C. THM analysis of a heating test in a fractured tuff. In: Stephansson O, Hudson JA, Jing L, editors. Coupled $\mathrm{T}-\mathrm{H}-\mathrm{M}-\mathrm{C}$ processes in geo-systems: fundamentals, modelling, experiments and applications. Oxford: Elsevier GeoEngineering Book Series; 2004. p. 181-6.

[9] Rutqvist J, Tsang CF, Tsang Y. Analysis of stress- and moistureinduced changes in fractured rock permeability at the Yucca Mountain Drift Scale Test. In: Stephansson O, Hudson JA, Jing $\mathrm{L}$, editors. Coupled $\mathrm{T}-\mathrm{H}-\mathrm{M}-\mathrm{C}$ processes in geo-systems: fundamentals, modelling, experiments and applications. Oxford: Elsevier Geo-Engineering Book Series; 2004. p. 161-6.

[10] Hsiung SM, Chowdhury AH, Nataraja MS. Thermal-mechanical modeling of a large-scale Heater Test. In: Stephansson O, Hudson JA, Jing L, editors. Coupled $\mathrm{T}-\mathrm{H}-\mathrm{M}-\mathrm{C}$ processes in geo-systems: fundamentals, modelling, experiments and applications. Oxford: Elsevier Geo-Engineering Book Series; 2004. p. $167-74$

[11] Olivella S, Gens A. Double structure THM analyses of a heating test in a fractured tuff incorporating intrinsic permeability variations. Int J Rock Mech Min Sc 2005, this volume.
[12] Hsiung SM, Chowdhury AH, Nataraja MS. Numerical simulation of thermal-mechanical processes observed at the Drift-Scale Heater Test at Yucca Mountain, Nevada, USA. Int J Rock Mech Min Sc 2005, this volume.

[13] Sonnenthal E, Ito A, Spycher A, Yui M, Apps J, Sugita Y, Conrad M, Kawakami S. Approaches to modeling coupled thermal, hydrological, and chemical processes in the Drift Scale Heater Test at Yucca Mountain. Int J Rock Mech Min Sc 2005, this volume.

[14] Wagner R. Thermal testing measurements report. ANL-NBS-HS000041 REV 00. Las Vegas, NV: Bechtel SAIC Company. ACC: MOL.20021004.0314; 2002.

[15] Birkholzer JT, Tsang YW. Pretest analysis of the thermal-hydrological conditions of the ESF Drift Scale Test. Milestone SP9322M4. Berkeley, CA: Lawrence Berkeley National Laboratory. ACC: MOL.19971201.0810; 1997.

[16] Birkholzer JT, Tsang YW. Modeling of thermal-hydrologic processes in a large-scale underground heater test in partially saturated tuff. Water Resour Res 2000;36(6):1431-47.

[17] Buscheck TA, Shaffer RJ, Nitao JJ. Pretest thermal-hydrological analysis of the Drift-Scale Thermal Test at Yucca Mountain. ACC: MOL.19980507.0359. Las Vegas, NV: CRWMS M\&O; 1997.

[18] Francis ND, Sobolik SR, Ho CK, Eaton RR, Preece D. Preexperiment thermal-hydrological-mechanical analyses for the ESF heated drift experiment. SLTR97-0002. Las Vegas, NV: CRWMS M\&O; 1997.

[19] Sobolik SR, Finley RE, Ballard S. Thermal-mechanical Measurements in the Drift Scale Test, Yucca Mountain, Nevada. In: Amadei B, Kranz RL, Scott GA, Smeallie PH, editors. Rock mechanics for industry. Proceedings of the 37th US rock mechanics symposium, Vail, CO, USA, vol. 2, June 6-9, 1999. Brookfield, VT: A.A. Balkema; 1999. p. 735-42.

[20] Blair SC. Coupled thermal-hydrologic-mechanical effects on permeability analysis and models report. ANL-NBS-HS-000037 REV 00. Las Vegas, NV: Bechtel SAIC Company; 2001.

[21] Tsang YW, Birkholzer JT. Predictions and observations of the thermal-hydrological conditions in the single Heater Test. J Contam Hydrol 1999;38(1-3):385-425.

[22] Sobolik SR, Finley RE, Ballard S. Post-test comparison of thermal mechanical measurements vs. Analyses for the in-situ single Heater Test, Yucca Mountain, Nevada. Int J Rock Mech Min Sci 1998;35(4-5):649.

[23] Nieder-Westermann GH. Geology of the Exploratory Studies Facility Topopah Spring loop. BAB000000-01717-0200-00002 REV01. Las Vegas, NV: Civilian Radioactive Waste Management System Management \& Operating Contractor (CRWMS M\&O); 1998.

[24] Wang J, Cook P, Trautz R, Flexser S, Hu Q, Salve R, Hudson D, Conrad M, Tsang Y, Williams K, Sol W, Turin J. In-situ field testing of processes ANL-NBS-HS-000005 REV01. Las Vegas, NV: Bechtel SAIC Company; 2001.

[25] Kessel D, Hayes L, Gilstrap OJ. Yucca Mountain site geotechnical report. B00000000-01717-5705-00043 REV 01. Two volumes. ACC: MOL.19971017.0736; MOL.19971017.0737. Las Vegas, NV: Civilian Radioactive Waste Management System Management \& Operating Contractor (CRWMS M\&O); 1997.

[26] Lee MY, Haimson BC. Initial stress in the Exploratory Studies Facility Yucca Mountain, Nevada. In: Amadei B, Kranz RL, Scott GA, Smeallie PH, editors. Rock mechanics for industry. Proceedings of the 37th US rock mechanics symposium, Vail, CO, USA, vol. 2, June 6-9, 1999. Brookfield, VT: A.A. Balkema, 1999. p. $743-50$.

[27] van Genuchten MT. A closed-form equation for predicting the hydraulic conductivity of unsaturated soils. Soil Sci Soc Am J 1980;44:892-8 
[28] Corey AT. The interrelation between oil and gas relative permeabilities. Producers Monthly November, 1954. p. 38-41.

[29] Civilian Radioactive Waste Management System Management \& Operating Contractor (CRWMS M\&O). TBV-332/TBD-325 resolution analysis: geotechnical rock properties. B0000000001717-5705-00134 REV 00, Las Vegas, NV, 1999.
[30] Rutqvist J, Tsang CF. Analysis of thermal-hydrologic-mechanical behavior near an emplacement drift at Yucca Mountain. J Contam Hydrol 2003;62-63:637-52.

[31] Bandis S, Lumsden AC, Barton NR. Fundamentals of rock joint deformation. Int J Rock Mech Min Sci Geomech Abstr 1983;20: 249-68. 